\section{Valores Inesperadamente Elevados de TSH: A Presença de Formas de Alto Peso Molecular ("Macro TSH”) Deve Ser Investigada}

\section{RESUMO}

As metodologias empregadas para a medida de TSH sérico apresentam niveis de especificidade e sensibilidade, tanto diagnósticas como analíticas, bastante elevadas. Adicionalmente, são metodologias bastante robustas, de maneira que resultados falso-positivos ou falso-negativos são raros e inesperados. Descrevemos neste trabalho dois casos de indivíduos descritos como eutiróideos, sem antecedentes de doenças autoimunes e sem referência ao uso de TSH exógeno, que apresentavam niveis de TSH de normais a muito elevados, dependendo da metodologia empregada. Em três métodos testados para a medida de TSH a diluição seriada das amostras mostrou que os niveis reais situavam-se entre 250 e $300 \mathrm{mUl} / \mathrm{L}$. Nos dois casos, o aumento de TSH foi ocasionado pela presença de proteínas ligadoras de TSH no soro, formando formas de alto peso molecular ("macro TSH"), demonstradas por cromatografia de gel filtração em coluna de Superdex S-200. Em uma das pacientes a proteína ligadora foi caracterizada como lgG através de cromatografia em proteína $G$ sepharose, na outra, a ligação em proteína $G$ e em coluna de sepharose acoplada a monoclonal anti-lgM não conseguiu caracterizar a proteína ligadora sérica. Estes casos salientam a importância da correlação clínico-laboratorial e sugerem a necessidade de se pesquisar a presença de macro TSH em pacientes com niveis de TSH anormalmente elevados. (Arq Bras Endocrinol Metab 2006;50/3:445-449)

Descritores: TSH sérico; Ensaios para medida de TSH; Interferentes em ensaios para TSH; Proteínas ligadoras de TSH

\begin{abstract}
Unexpected High Values of TSH: The Presence of High Molecular Weight Forms (Macro TSH) Must Be Investigated.

The laboratory methods usually employed for the measurement of serum TSH present sensitivity and specificity levels, both analytical and clinical, that are highly satisfactory. Additionally, the methodologies are quite robust, so that false-positive and false-negative results are rare and unexpected. In this paper we describe two individuals quoted as euthyroid clinically, with no reference to autoimmune diseases, and no reference to the use of exogenous TSH, that presented with normal to extremely high serum TSH levels, depending on the method employed for analysis. In the three tested methods, serial dilution showed that the real TSH levels were between 250 and $300 \mathrm{mUI} / \mathrm{L}$. In both cases the increment in TSH levels were due to the presence of TSH-binding proteins, forming high molecular weight complexes ("macro TSH"), well characterized by gel filtration chromatography on Superdex S-200 column. In one of the patients the binding protein was characterized as being $\lg G$ by protein- $G$ binding study. In the other case, protein- $G$ binding as well as anti-lgM binding failed to characterize the protein. These two cases call attention to the importance of the clinical-laboratory correlation and suggest the need that the presence of "macro TSH" must be investigated in patients with unexpectedly high TSH values. (Arq Bras Endocrinol Metab 2006;50/3:445-449)
\end{abstract}

Keywords: Serum TSH; TSH assays; Interferents in TSH assays; TSH binding proteins artigo original

\author{
José Gilberto H. Vieira \\ Rui M.B. Maciel \\ Omar M. Hauache \\ Sônia K. Nishida \\ Dalva M.G. Boelter \\ Maria F.M.C. Pinbeivo
}

Setor de Endocrinologia do

Laboratório Fleury (JGHV, RMBM, OMH, SKN), São Paulo, $S P$; e do Laboratório Sérgio Franco

(DMGB, MFMCP), Rio de Janeiro, $R J$.

Recebido em 01/08/05

Revisado em 26/12/05 Aceito em 23/01/06 
A DOSAGEM DE TSH é a dosagem hormonal mais solicitada na prática clínica. Devido à sua alta sensibilidade e especificidade, é o exame de primeira linha no diagnóstico laboratorial tanto de hipo como de hipertiroidismo (1). O ensaio universalmente empregado hoje em dia para a dosagem de TSH sérico segue um desenho imunométrico não-competitivo, geralmente empregando dois anticorpos monoclonais (produzidos a partir de camundongos), um de captura e outro de revelação (2). A possibilidade de interferências neste tipo de ensaio é bastante remota, porém real, sendo o tipo mais comum a presença de anticorpos heterofílicos (3). Neste tipo de interferência, ocasionada por anticorpos endógenos que reconhecem estruturas presentes na imunoglobulina de camundongo, podemos observar resultados falsamente elevados (mais comumente) ou falsamente baixos. Uma série de medidas técnicas, dentre elas a adição de um excesso de imunoglobulinas inespecíficas de camundongo aos tampões de ensaio, foram incorporadas visando prevenção deste tipo de fenômeno, com resultados bastante satisfatórios. No entanto, resultados falsos podem ainda ocorrer, e a suspeita e procura da etiologia do fenômeno devem ser uma preocupação contínua dos profissionais envolvidos.

A interferência de anticorpos endógenos dirigidos contra hormônios peptídeos é um fenômeno conhecido e bem descrito. Estes ocorrem sabidamente contra insulina, hormônio de crescimento e, especialmente, contra prolactina, sendo neste último caso responsáveis pelo fenômeno da macroprolactina (4). São, no entanto, raros os casos descritos de presença de anticorpos dirigidos contra hormônios glicoprotéicos, tendo sido descritos poucos casos de anticorpos anti-TSH $(5,6)$. Recentemente descrevemos o primeiro caso comprovado de presença de anticorpos endógenos anti-LH (7).

Nesta comunicação, relatamos dois casos de indivíduos que apresentaram valores surpreendentemente elevados de TSH devido à presença de proteínas ligadoras de TSH no soro, configurando o fenômeno de "macro TSH".

\section{INDIVÍDUOS}

$\mathrm{O}$ primeiro indivíduo (indivíduo A) era uma mulher de 53 anos com diagnóstico de hipotiroidismo há dois anos, em função do encontro de níveis de TSH elevados. $\mathrm{O}$ tratamento substitutivo iniciado não normalizou os níveis de TSH apesar de elevar os níveis de T4 livre. A dissociação entre resultados de TSH por metodologias diferentes no laboratório de origem chamou a atenção, sendo o material encaminhado ao nosso laboratório para estudos adicionais. $\mathrm{O}$ segundo indivíduo (indivíduo B), também do sexo feminino, de 6 anos de idade, foi investigado por suspeita de retardo de crescimento. Não apresentava sinais clínicos de hipotiroidismo, com níveis de T4 livre normais e de TSH elevados, mas também com valores discrepantes em duas metodologias diferentes, o que prontificou o envio do material para estudos adicionais em nosso laboratório. Nenhum dos dois fazia uso de reposição de hormônios tiroideanos por ocasião do estudo.

\section{MATERIAL E MÉTODOS}

TSH foi dosado por ensaio imunofluorométrico (IFMA) baseado em anticorpos monoclonais desenvolvido em nosso laboratório (8). Outros métodos empregados para dosagem de TSH foram os ensaios imunoquimioluminométrico (IQMA) (Advia Centaur) e eletroquimioluminométrico (ECLIA) (Roche). Os ensaios de T4 livre foram realizados por fluoroimunoensaio (PerkinElmer), a pesquisa de anticorpos anti-TPO e anti-receptor de TSH por radioensaio (BRAHMS), e a pesquisa de anticorpos anti-Tiroglobulina por ensaio fluorométrico (9). A precipitação do soro com polietilenoglicol seguiu a metodologia descrita para a pesquisa de macroprolactina (4). A cromatografia em coluna de gel filtração empregou coluna de Superdex 200 (1,5 x $30 \mathrm{~cm}$, Pharmacia), calibrada com marcadores de alto peso molecular, em tampão neutro. A mesma coluna foi empregada para cromatografia em condições dissociantes através do emprego de tampão glicina- $\mathrm{HCl}$ 0,1 M, pH 2,8. Foi empregada também, como resina ligadora de IgG, uma coluna de proteínaG sepharose (Pharmacia), eluída inicialmente com tampão neutro e em seguida com tampão $\mathrm{pH} \mathrm{2,8.} \mathrm{A}$ coluna de sepharose acoplada com anticorpo monoclonal anti-IgM humano foi preparada em nosso laboratório utilizando sepharose ativada com brometo de cianogênio (Pharmacia) e anticorpo monoclonal por nós desenvolvido.

\section{RESULTADOS}

O indivíduo A apresentava níveis de TSH que, com o ensaio IQMA, variaram entre 1,4 e 24,2 mUI/L e com ensaio ECLIA entre 64,7 e superior a $100 \mathrm{mUI} / \mathrm{L}$ no laboratório de origem. Em nosso laboratório, empregando o ensaio IFMA, o resultado foi de 10,0 
mUI/L e, empregando o ensaio ECLIA, de 250 $\mathrm{mUI} / \mathrm{L}$, resultado este obtido após diluição da amostra. Diluições seriadas da amostra com posterior dosagem no ensaio IFMA mostraram não-paralelismo, ou seja, os valores obtidos foram crescentes até uma diluição de $1: 100$, quando chegaram a aproximadamente $250,0 \mathrm{mUI} / \mathrm{L}$. O soro foi então submetido a cromatografia em coluna e o resultado encontra-se representado na figura 1. Observamos que a cromatografia do soro em condições neutras mostrou um pico de imunorreatividade para TSH de alto peso molecular (correspondente a um peso molecular superior a $200 \mathrm{kDa}$ ). Na mesma coluna, um soro de uma paciente com hipotiroidismo primário e com níveis de TSH séricos de 125,0 $\mathrm{mUI} / \mathrm{L}$ mostrou imunorreatividade para TSH com peso molecular correspondente ao TSH monomérico $(28 \mathrm{kDa})$. O soro do indivíduo $\mathrm{A}$, quando aplicado à coluna de proteína-G sepharose, mostrou um comportamento compatível com a presença de imunoglobulina em conjunto com TSH, e que pode ser visto na figura 2; a imunorreatividade de TSH foi retida pela coluna e só eluída em condições dissociantes. Em outras palavras, a coluna de proteína-G, que liga imunoglobulina, capturou o TSH pois este estava ligado a uma IgG. A eluição em condições

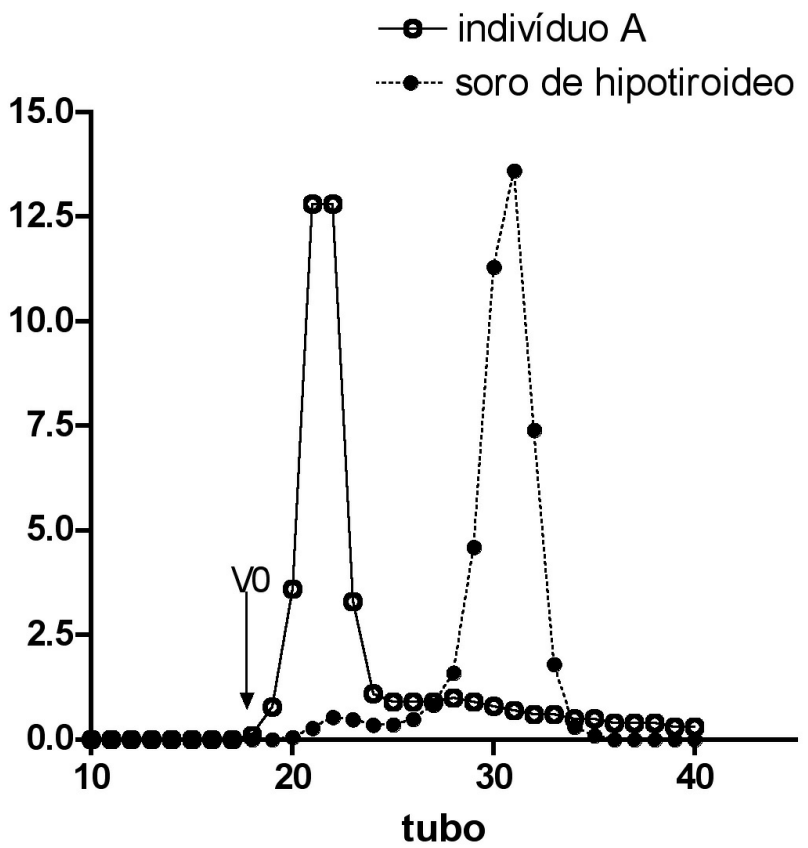

Figura 1. Perfil de eluição obtido em coluna de Superdex $200(1,5 \times 30 \mathrm{~cm})$ com o soro do indivíduo $\mathrm{A}(\mathrm{O})$, em condições neutras, e com soro de paciente portadora de hipotiroidismo $(\bullet)$ (TSH: 125,0 mUI/L). V0 indica o volume de exclusão da coluna. dissociantes liberou a IgG da coluna e, conseqüentemente, o TSH a ela ligado. A precipitação com PEG mostrou recuperação de apenas 3,6\%, compatível com presença predominante de TSH ligado a imunoglobulinas. Os níveis de T4 livre eram normais $(1,2 \mathrm{ng} / \mathrm{dL}$, normal de $0,7 \mathrm{a} 1,5 \mathrm{ng} / \mathrm{dL})$ e a pesquisa de anticorpos anti-receptor de TSH, anti-TPO e antitiroglobulina, negativos.

$\mathrm{O}$ indivíduo $\mathrm{B}$ apresentava níveis de TSH com o ensaio IQMA de $12,0 \mathrm{mUI} / \mathrm{L}$, e com ensaio ECLIA superior a $100 \mathrm{mUI} / \mathrm{L}$. No ensaio IFMA, o valor foi de 2,7 mUI/L na dosagem direta, mas com diluições sucessivas repetiu-se o fenômeno de não paralelismo observado no soro do indivíduo $\mathrm{A}$, e o valor final obtido foi de $300 \mathrm{mUI} / \mathrm{L}$. A cromatografia em coluna de gel filtração mostrou também a imunorreatividade de TSH eluindo com alto peso molecular (> $200 \mathrm{kDa}$ ) em tampão neutro e eluindo no ponto esperado para TSH quando em condições dissociantes, quando o TSH não se liga à proteína carregadora presente (figura 3 ). A precipitação com PEG mostrou resultado intermediário (56\%) e a aplicação em coluna de proteína-G sepharose não mostrou ligação da imunorreatividade de TSH, afastando IgG como a proteína ligadora. A cromatografia em coluna de sepharose acoplada a um

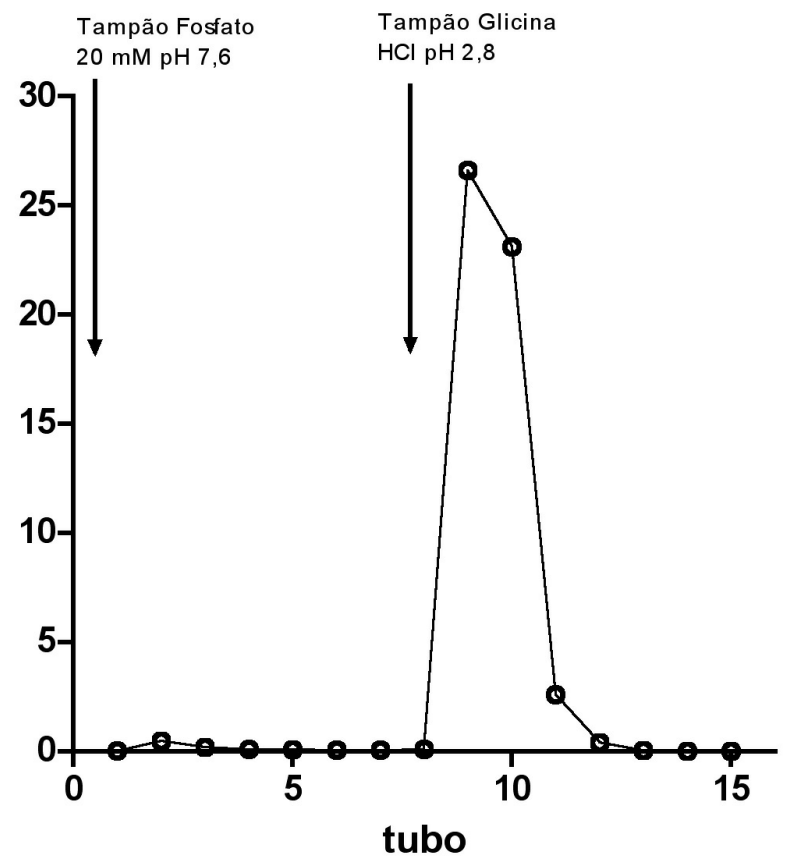

Figura 2. Perfil de eluição obtido com soro do indivíduo $A$ aplicado em coluna de proteína- $G$ Sepharose. A ligação do TSH à coluna indica que este está ligado a uma lgĞ. A troca de tampão, para uma condição dissociante, provocou a eluição da imunorreatividade de TSH. 
monoclonal anti-IgM humana também não mostrou ligação. Os níveis de T4 livre também eram normais $(1,3 \mathrm{ng} / \mathrm{dL})$ e as pesquisas de anticorpos anti-receptor de TSH, anti-TPO e anti-tiroglobulina, negativas.

\section{DISCUSSÃO}

Anticorpos anti-TSH foram reportados classicamente em pacientes que receberam injeções de TSH bovino como estimulante da função tiroideana em procedimentos diagnósticos e terapêuticos $(10,11)$. No entanto, a presença de anticorpos anti-TSH foi também descrita em pacientes com doenças auto-imunes de tiróide, em especial em pacientes com doença de Graves $(12,13)$. Neste último caso, os anticorpos poderiam se tratar de anticorpos anti-idiotípicos contra anticorpos anti-receptor de TSH presentes nesses pacientes. A descrição de anticorpos endógenos antiTSH em pacientes que não apresentam doença autoimune de tiróide ou não receberam injeções de TSH bovino é fenômeno raro $(5,6,14)$. Sua indução pelo uso de preparações de TSH humano recombinante parece não ser problema semelhante ao que era observado quando do emprego de preparações de TSH bovino (15).

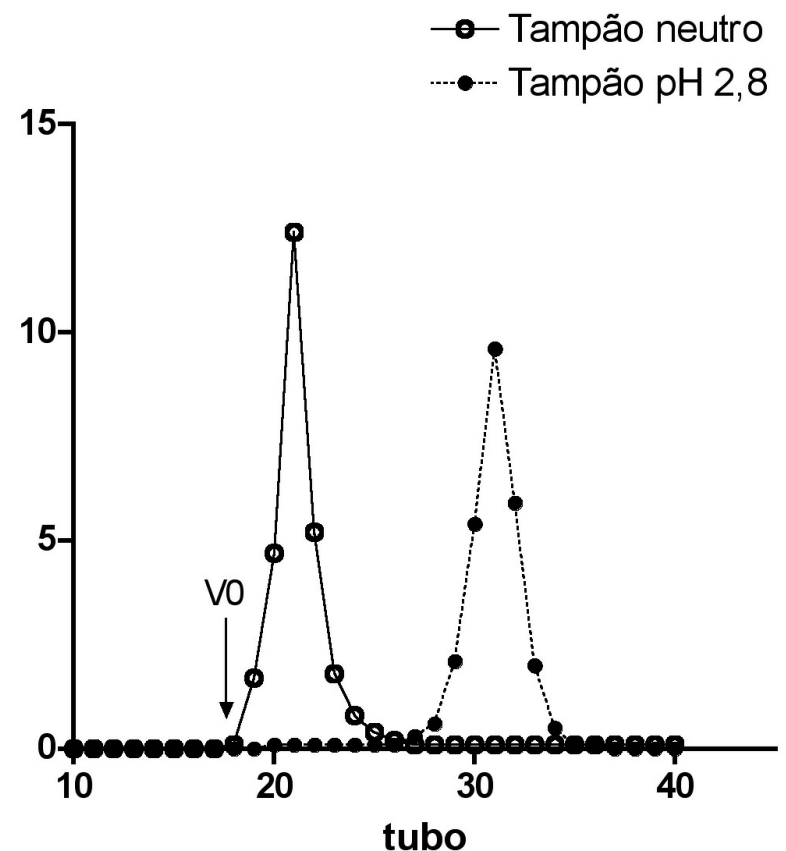

Figura 3. Perfil de eluição obtido com o soro do indivíduo $B$ em coluna de Superdex $200(1,5 \times 30 \mathrm{~cm})$ com tampão neutro $(0)$ e com tampão dissociante $\left(\mathrm{pH}_{2}, 8\right)(\bullet)$. Nesta última condição, o deslocamento do pico de TSH mostra que o mesmo estava ligado a uma macromolécula.
Os dois casos aqui descritos não apresentavam evidências de presença de doença auto-imune de tiróide, nem haviam recebido injeções de TSH bovino ou humano. $\mathrm{O}$ que chamou a atenção nos dois casos foram os valores inesperadamente elevados de TSH, com níveis de T4 livre normais e com quadro clínico não compatível. No caso do indivíduo $\mathrm{A}$, o interferente era comprovadamente a presença de anticorpos IgG anti-TSH. Já no caso do indivíduo B, apenas pudemos comprovar a presença de uma substância de alto peso molecular que se liga à TSH, sem ser caracterizada como $\operatorname{IgG}$ ou $\operatorname{IgM}$. Sua caracterização ainda deve ser estudada. Os resultados falsamente baixos observados em dois dos ensaios empregados, comprovados pela falta de paralelismo pós-diluição observada, comprovam diferentes graus de interferência nos diferentes ensaios. Estes achados podem ser devidos a uma coincidência de epítopos reconhecidos pelos diferentes monoclonais empregados, ou de diferenças nos desenhos dos ensaios, possibilitando o deslocamento ou não do TSH endógeno das proteínas ligadoras. Muito provavelmente as diferenças de desenho se caracterizam pela maior exposição aos anticorpos proporcionado pelo uso de micropartículas, como no caso do ICLA empregado neste estudo.

Nossos achados mostram que a presença de um fenômeno de "macro TSH" deve ser aventada em pacientes com níveis de TSH surpreendentemente altos, não compatíveis com o quadro clínico e com os níveis de T4 livre. O fenômeno pode ocorrer mesmo em indivíduos sem doenças autoimunes de tiróide, e, devido à sua heterogeneidade, deve ser comprovado por cromatografia em coluna de gel filtração.

\section{REFERÊNCIAS}

1. Ladenson PW, Singer PA, Ain KB, Bagchi N, Bigos ST, Levy $E G$, et al. American Thyroid Association guidelines for detection of thyroid dysfunction. Arch Intern Med 2000; 160:1573-5.

2. Vieira JGH, Lombardi MT, Nishida SK. Anticorpos monoclonais contra hormônios glicoprotéicos: produção, características gerais e implicações metodológicas. Arq Bras Endocrinol Metab 1994;38:157-63.

3. Bjerner J, Nustad K, Norum LF, Olsen KH, Børmer OP. Immunometric assay interference. Incidence and prevention. Clin Chem 2002;48:613-21.

4. Vieira JGH, Tachibana TT, Obara LH, Maciel RMB. Extensive experience and validation of polyethylene glycol precipitation as a screening method for macroprolactin. Clin Chem 1998;44:1758-9. 
5. Spitz IM, Roith DL, Hirsch H, Carayon P, Pekonen F, Liel Y, et al. Increased high-molecular-weight thyrotropin with impaired biologic activity in a euthyroid man. N Engl J Med 1981;304:278-82.

6. Sapin R, d'Herbomez M, Schlienger JL, Wemeau JL. Antithyrotropin antibody interference in thyrotropin assays. Clin Chem 1998;44:2557-9.

7. Vieira JGH, Nishida SK, Camargo MTF, Hauache OM, Maciel RMB, Guimarães V. "MacroLH": anomalous molecular form that behaves as a complex of luteinizing hormone (LH) and $\lg G$ in a patient with unexpectedly high LH values. Clin Chem 2003;49:2104-5.

8. Vieira JGH, Kunii IS, Nishida SK, Matsumura LK, Russo EMK, Maciel RMB. Desenvolvimento e aplicação de um método imunofluorométrico para a dosagem de tirotrofina humana (TSH) no soro e em sangue total colhido em papel de filtro. Arq Bras Endocrinol Metab 1992;36:7-12.

9. Vieira JGH, Tachibana TT, Fonseca RMG, Nishida SK, Maciel RMB. Desenvolvimento de um método imunofluorométrico para a medida de anticorpos séricos contra tiroglobulina. Arq Bras Endocrinol Metab 1996:40:232-7.

10. Hays MT, Solomon DH, Beall GN. Suppression of human thyroid function by antibodies to bovine thyrotropin. J Clin Endocrinol Metab 1967:27:1540-9.
11. Melmed S, Harada A, Hershman JM, Krishnamurthy GT, Blahd WH. Neutralizing antibodies to bovine thyrotropin in immunized patients with thyroid cancer. J Clin Endocrinol Metab 1980;27:1540-9.

12. Ochi $Y$, Nagamune T, Nakajima $Y$, Ishida $M$, Kajita $Y$, Hachiya T, et al. Anti-TSH antibodies in Graves' disease and their failure to interact with TSH receptor antibodies. Acta Endocrinol (Kbh) 1989; 120:773-7.

13. Beall GN, Kruger SR. Binding of 125- I human TSH by gamma globulins of sera containing thyroid-stimulating antibodies (TSI). Life Sci 1983;32:77-83.

14. Tamaki $H$, Takeoka K, Nishi I, Shindoh Y, Tsukada Y, Amino N. Novel thyrotropin (TSH)-TSH complex in a healthy woman and her neonates. Thyroid 1995;5:299-303.

15. Ramirez L, Braverman LE, White B, Emerson CH. Recombinant human thyrotropin is a potent stimulator of thyroid function in normal subjects. J Clin Endocrinol Metab 1997;82:2836-9.

\section{Endereço para correspondência:}

José Gilberto H. Vieira

Laboratório Fleury

Av. General Waldomiro de Lima 508

04344-070 São Paulo, SP

E-mail: jose.vieira@fleury.com.br 